\title{
Influence of microscopic casting defects on fatigue endurance of ductile cast iron
}

\author{
František Nový ${ }^{1, *}$, Peter Kopas $^{2}$, Otakar Bokůvka ${ }^{1}$, Michal Jambor ${ }^{1,3}$, Libor Trško ${ }^{3}$ \\ ${ }^{1}$ University of Zilina, Faculty of Mechanical Engineering, Department of Material Engineering, \\ Univerzitná 1, 010 26, Zilina, Slovak Republic \\ ${ }^{2}$ University of Zilina, Faculty of Mechanical Engineering, Department of Applied Mechanics, \\ Univerzitná 1, 010 26, Zilina, Slovak Republic \\ ${ }^{3}$ Research Centre of the University of Žilina, Univerzitná 1, 010 26, Zilina, Slovak Republic
}

\begin{abstract}
In this work, there are published results about fatigue endurance of ductile cast iron obtained at high-frequency sinusoidal cyclic push-pull loading in the ultrahigh cycle fatigue region. The main attention was focused on the fatigue lifetime data scatter caused by the influence of microscopic casting defects (microshrinkages, microbubbles, microcracks, non-metallic inclusions and local clusters of big graphitic nodules).
\end{abstract}

Keywords: ultra-high cycle fatigue, microscopic casting defects, microshrinkages, microbubbles, microcracks

\section{Introduction}

Graphite cast irons are the important group of cast structural materials, with the wide range of application in the industry. The special important is the group of cast irons with the spheroidal shape of graphite particles (LGG), which are frequently used in the automotive industry and in the heavy earthmoving machinery. Their wide range of applications is due to their economist, good technological properties and their ability to damp vibrations. In the most applications, the components made from the cast iron are exposed to the time-varying loading during their operating. Fatigue properties of LGG, despite intensive research, are not yet fully described. It is well known, that fatigue tests of this category of materials show a significant scattering of the measured data. The magnitude of this scattering is most often justified by the presence of structural heterogeneities and the casting defects, which significantly affect the fatigue properties [1-8].

Since requirements for the reliability and quality of castings has a steadily rising tendency, improving and the developing of the new methods and devices for the quality control and its testing are necessary. Every product made by the casting technology contains some defects or heterogeneities, which assessment and tolerance should depend on the purpose of the casted parts. The admissibility of the individual defects and their size is usually given in the acceptance protocol. In real practice, the wide range of casting defects

\footnotetext{
* Corresponding author: frantisek.novy@,fstroj.uniza.sk

Reviewers: Zuzana Murčinková, Bohuš Leitner
} 
appears in the casted parts. Among the most difficult to detect are cavities, micro-cavities, inclusions, structural heterogeneities and the different grains size, and its detection is required especially for parts with guaranteed mechanical and fatigue properties.

Authors in this study present their own experimental results of the influence of small (microscopic) casting defects on the ultra-high cycle fatigue properties of LGG.

\section{Experimental material and procedures}

\subsection{Material}

Experiments were carried out on the specimens from the two melts of LGG, whose chemical composition and the mechanical properties are shown in the Tab.1. The first melt (designated as A) represents the pearlitic-ferritic LGG, with the $4 \%$ volume fraction of ferrite in the structure. The second melt, (designated as B) is the ferritic-pearlitic LGG with the $25 \%$ volume fraction of the perlite in the structure. Both melts were tested in the as-cast state, without any following heat treatment (Fig. 1 and Fig. 2).

Table 1. Chemical composition and the mechanical properties of used LGGs

\begin{tabular}{|c|c|c|c|c|c|c|c|c|c|}
\hline \multirow{8}{*}{ melt } & $\mathbf{C}$ & Mn & Si & P & S & Cu & Mo & \multirow{2}{*}{ HB 5/2450/10 } & UTS \\
\cline { 2 - 6 } & \multicolumn{8}{|c|}{ weight \% } \\
\hline A & 3.55 & 0.53 & 3.01 & 0.030 & 0.033 & 0.49 & 0.025 & 224 & 702 \\
\hline B & 3.38 & 0.08 & 2.93 & 0.037 & 0.012 & 0.02 & 0.037 & 144 & 480 \\
\hline
\end{tabular}

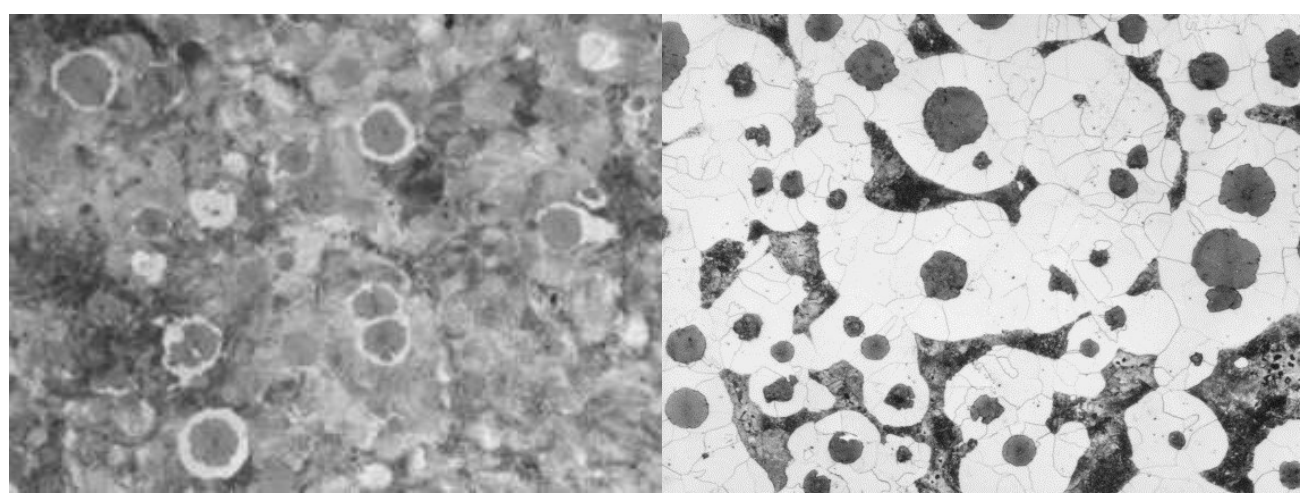

Fig. 1. Structure of the perlitic-feritic LGG (A), etch. $3 \%$ Nital, mag. $100 \mathrm{x}$
Fig. 2. Structure of the feritic-perlitic LGG (B), etch. $3 \%$ Nital, mag. $100 \mathrm{x}$

\subsection{Casting defects causes of their formation}

One fifth of the overall scraps of castings in the foundries is due to cavities. The castings with these defects are mostly unrepairable and in the production of a casting of the dynamically loaded parts with such errors should be discarded. These defects are caused by the presence of gases in the molten metals and the form and by the volume changes of the casting during the solidification of metal.

According to their size, they can be divided into macroscopic cavities (bubbles, shrinkages, shrinkage porosity, slags, cracks), and microscopic cavities (microbubbles, microshrinkages, microcracks). 
There are two main types of porosity namely gas porosity and shrinkage porosity. In case of gas porosity, the shape of the bubbles (Fig. 3) is very diverse and they could be present in the spherical to ellipsoidal shape but also they could have irregular, elongated shape. Bubbles can be divided by origin to endogenous and exogenous. Endogenous bubbles forms from the gases dissolved in the molten metal when the pressure of the dissolved gasses exceeds the resistance against them. Endogenous closed bubbles have the metallic shiny, unoxidized surface of the walls, or covered with just a thin oxide layer. Exogenous bubbles are formed during casting if the gas pressure in the casting area exceeds the pressure of the solidifying surface of the molten metal and the gases penetrate to the casting. In such a case they can be also classified as a flooded gas. These defects have many common characteristics and often it is not possible to clearly distinguish these two types of casting defects. The susceptibility to bubble formation increases with the increasing wall thickness of castings and decreases with the increasing metallostatic pressure. These conclusions are based on the theory of heterogeneous nucleation of bubbles in castings and proved by the practical experiences. When assessing the susceptibility of casting to the formation of hydrogen, oxygen and nitrogen bubbles, the high content of carbon and silicon and their impact on the solubility limits of oxygen, hydrogen, and nitrogen in the cast iron must be taken into account. Carbon and silicon increase the solubility limits of oxygen, but at the same time reduce the solubility of hydrogen and nitrogen in the cast iron. Increasing carbon and silicon content restrict its own solubility in the cast iron. All types of bubbles have a common the underlying cause. Temperature drop during the casting and cooling of the metal decreases the solubility limits of gases in the metal and when this limit value of the solubility depending on the temperature, pressure, and composition is exceeded, the gases are excreted which result in the bubbles formation. This takes place by the mechanism of heterogeneous nucleation. Hydrogen and nitrogen bubbles are formed during solidification of the cast iron due to supersaturation of the melt by dissolved hydrogen and nitrogen. Oxygen (except the absorbed atmospheric oxygen and the water vapor) does not cause the bubble formation directly but through reaction with the carbon in molten or solid metal, which result in the formation of carbon monoxide. Bubbles made by the carbon monoxide are mostly concentrated in the near surface regions and if they are not directly connected with the free surface, their surface does exhibit neither decarburization nor oxidization. The main causes of the bubbles formation in cast iron castings are: using of inappropriate batch (large volumes of many times re-melted waste, use of corroded, wet and not blasted waste and the general use of the wet batch), unnecessary prolongation of melting process and insufficient deaeration of molds and cores, combined with their high moisture level. After pouring the molten metal into the mold cavity of sand form, a large number of gases and vapors are produced. Their amount and nature depend on the type of used molding mixtures, the weight of casting etc. In the raw molds, the moisture contained in the molding mixture is immediately converted to vapor what results in the generating considerable pressure of gases on the mold-metal interface in both directions (towards the mold and towards the metal). At this stage, two factors determine the gas flow direction, namely the permeability of the molding mixture and the crystallization process of the casting. At this moment, the metallic crust on the casting surface is of great significance, as it is impermeable. Compressed gases try to escape from their origins through the least resistance. If the permeability of the molding mixture is sufficient, the gases penetrate throughout the grains of forming material to the environment. Otherwise, the partial pressure of the gases will increase at the mold-metal interface and therefore there is the danger that the gases will penetrate into the crystallizing casting and form the slags. The formation of slags and sand blow of mold or cores is unambiguous and is related to releasing of water vapor or the gases from the organic substances contained in the raw molding mixture or in the binder of synthetic resin mixtures [9]. 
Shrinkage is the most common type of casting defect. There are four types of shrinkage that can occur in metal castings: cavity, sponge, filamentary and dendritic. Cavity shrinkage occurs when two different sources of molten material are joined to create a common front while solidification is already taking place. A lack of additional feed material to fill in the accumulating gaps can further exacerbate the cavity shrinkage problem. Sponge shrinkage arises in the thicker mid-section of the casting and causes a thin lattice texture similar to filament or dendrites develop. Filamentary shrinkage results in a network of continuous cracks of various dimensions and densities, usually under a thick section of the material. It can be difficult to detect and the fracture lines tend to be interconnected. Dendritic shrinkage or dendritic fractures are narrow, randomly distributed lines or cavities that are often unconnected. They are typically thinner and less dense than filamentary cracks.

Internal closed shrinkages have an irregular shape, influenced by the different rates of heat removal from the mold wall and edges, cores, the inlet systems etc. At their nonoxidized surfaces are dendrites of varying size. Usually, they are found at the heat center or under the solidified part of casting in the lower parts of casting with the interrupted supply of molten metal while this part is not still solidified. They are formed due to reducing the metal volume upon its solidification.

The shrinkage porosity (Fig. 4) can be characterized as small shrinkages which are formed in the heat center of the casting. They form in the final stage of solidification due to bulk volume shrinking in the case of imperfectly directed metal solidification. In the casting, generally, local cluster or chains of shrinkage porosity are formed along the entire length or height of the casting in its thermal axis. The clusters of shrinkage pores are most often formed in the thicker walls or their connections, or in the other local thermal centers of the casting.

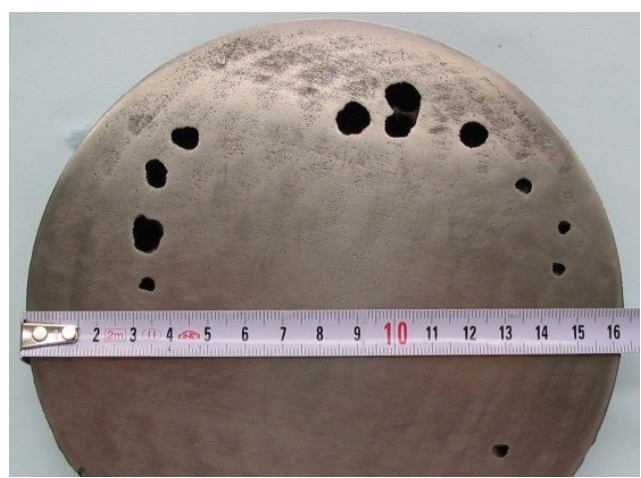

Fig. 3. Bubbles

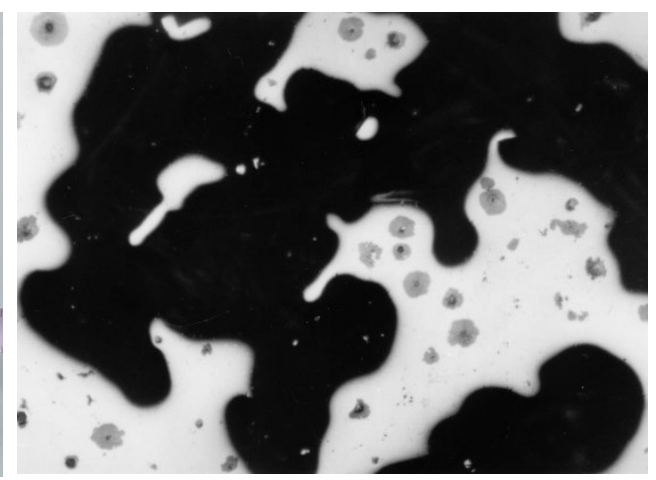

Fig. 4. Shrinkage porosity, magnification $50 \mathrm{x}$

The principal causes of the microscopic bubbles formation (microbubbles, micro shrinkages, and microcracks) are similar as in the macro defects formation (bubbles, shrinkages, and hot-cracks). Similarly, they differ in both, the morphology and in the physical nature of their origin.

Microbubbles, small spotted cavities, are formed during the solidification of the alloy, just after the previous dendrite solidification, which are the most favorable places for their heterogeneous nucleation. They form due to supersaturation of the molten metal with the dissolved gases, with the same mechanism as the endogenous bubbles, but with the difference that their growth stage is limited as a consequence of significantly lower concentrations of the dissolved gases in the molten metal than in the case of large bubbles. Microbubbles are sometimes occurring together with the macroscopic bubbles and they often form in the combination with microshrinkages. The microshrinkages (Fig. 5) have predominantly crystalline character (Fig. 6) and they are formed during the solidification in the dendrites contact areas of grains of solidifying alloy. They are most often formed at 
places with limited molten metal supply and in alloys with long solidification interval and large shrinkage coefficient. During solidification, the most of additives, alloying elements and impurities are displaced to the remaining molten metal in the interdendritic spaces, which result in decreasing of solidus temperature and caused the formation of brittle phases and eutectics, which subsequently serves as a micro cracks sources. The microshrinkages surface is formed by a rounded end of the higher order dendrites, which growth has stopped on the closed surface of microshrinkages due to the stopped supply of the molten metal.

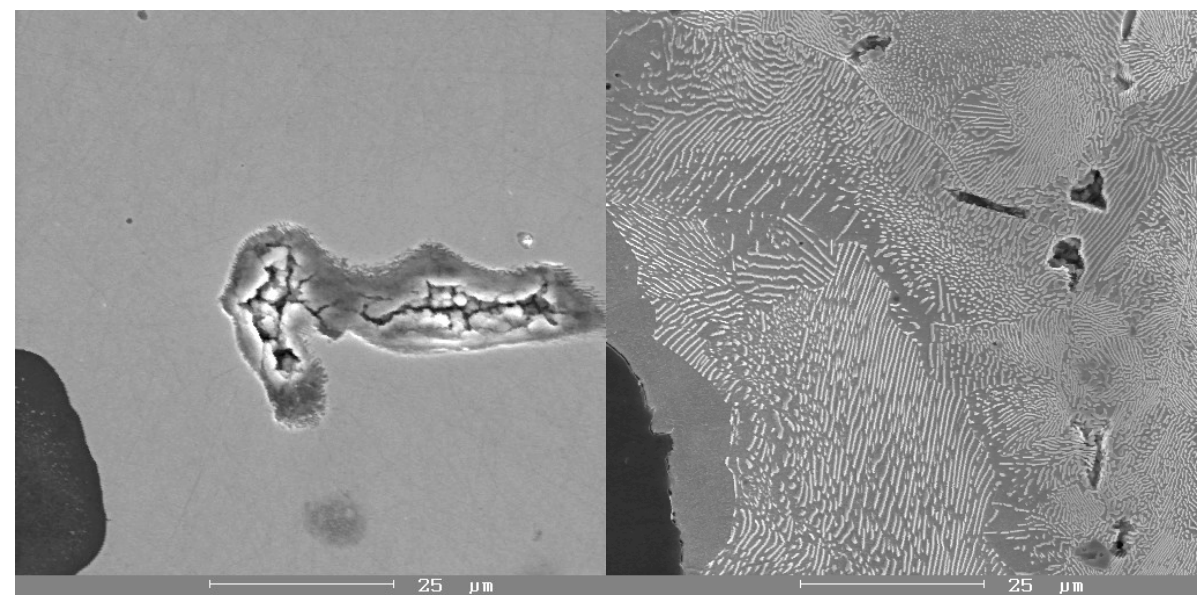

Fig. 5. Detail of microshrinkage

Fig. 6. Intercrystalline microshrinkages

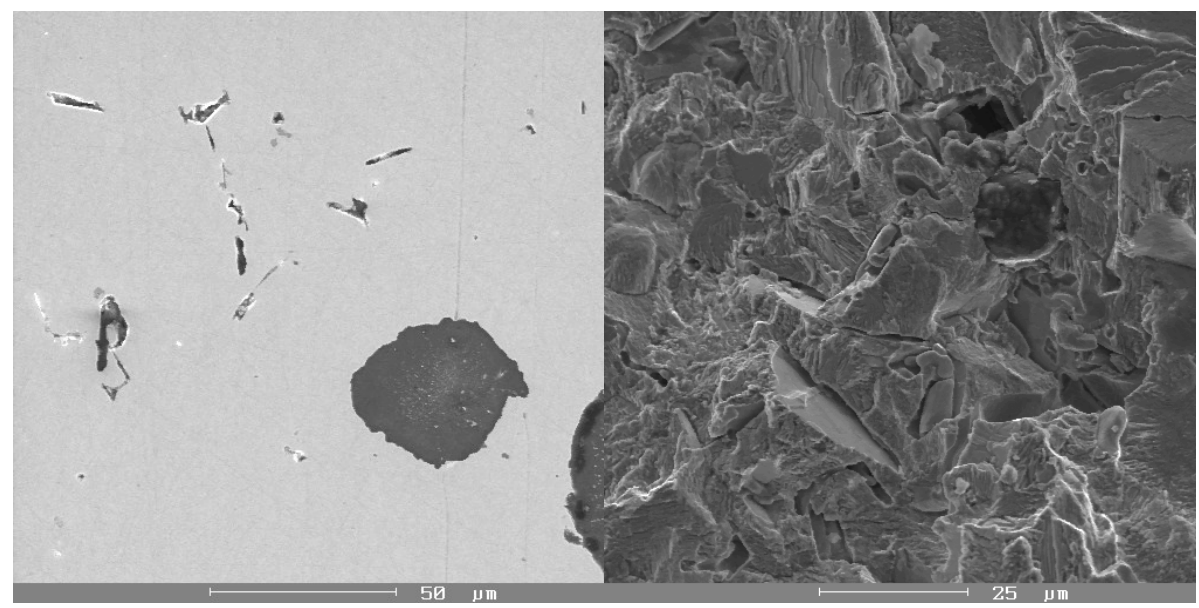

Fig. 7. Microshrinkages and microcracks

Fig. 8. Microshrinkages and microcracks on the fracture surface of the broken specimen

A sequence of defects the microbubble and the microshrinkage very often end with a formation of microcracks at high or lower temperatures. Microcracks start to form preferentially at the dendrites or grain boundaries, but also in the dendrite and grain interiors. The formation of microcracks along the dendrites and grains boundaries is characteristics for the high-temperature crack formation. The microcracks formation in the dendrite and grain interiors is more frequently at lower temperature levels and usually is associated with the phase transformations. This division of microcracks is just approximate, and origin of individual microcracks must be examined carefully. Microcracks very often 
coexist together with the microshrinkages, and they continuously pass into each other which make very difficult to distinguish them (Fig. 7 and Fig. 8). In the cast iron castings, which are much more heterogeneous than steel castings, the microscopic cavities are usually located at the peripheral regions of eutectic cells, most often at the point of contact of the several cells.

\subsection{Fatigue tests}

The fatigue tests were carried out on the ultrasonic fatigue testing system KAUP-ŽU, which is more detailed described in the works $[10,11]$ and the specimens were loaded by the highfrequency tension-compression sinusoidal loading $\left(f \approx 20 \mathrm{kHz}, R=-1, T=20 \pm 10^{\circ} \mathrm{C}\right.$, specimens were cooled by submerging in the water with anticorrosion inhibitor). The surface of the specimen's middle section was ground and polished to eliminate any possible influence of the surface state on the fatigue properties.

\section{Results}

Theory of permissible defects and the linear fracture mechanics, which are used in the fatigue life prediction of parts containing casting macro defects, are well described. But these are applicable only to the low cycle fatigue $\left(N<10^{6}\right.$ cycles $)$. The effect of the microscopic casting defects on the fatigue properties is usually examined in the high cycle region $\left(N \approx 10^{8}\right.$ cycles) and the very high cycle region $\left(N>10^{9}\right.$ cycles). This reflects the fact that unlike in the low cycle fatigue, where the fatigue behaviour of the materials is generally controlled by the fatigue crack propagation process (initiation stage is neglected), the fatigue properties in the very high cycle region are determined by the initiation stage of the fatigue process. Due to a limited scope of the paper, the following part will deal only with the examination of microscopic cavities effect on the fatigue life of the LGG in the very high cycle region.

The result obtained from the experimental measurement of the fatigue life of the ferritic-pearlitic and pearlitic-ferritic LGGs in the very high cycle region depicted as a function $\sigma_{a}=f(N)$ in the Fig. 9 shows a high degree of scattering. Scattering of the fatigue life values increases with the decreasing amplitude of cyclic loading. Such a large scattering in the fatigue life of LGG in the very high cycle region are provable caused by the microscopic casting defect such as microbubbles, microshrinkages, microcracks, inclusions, a local cluster of graphite particles, imperfectly spheroidal graphite, structural heterogeneity and different grain size. 


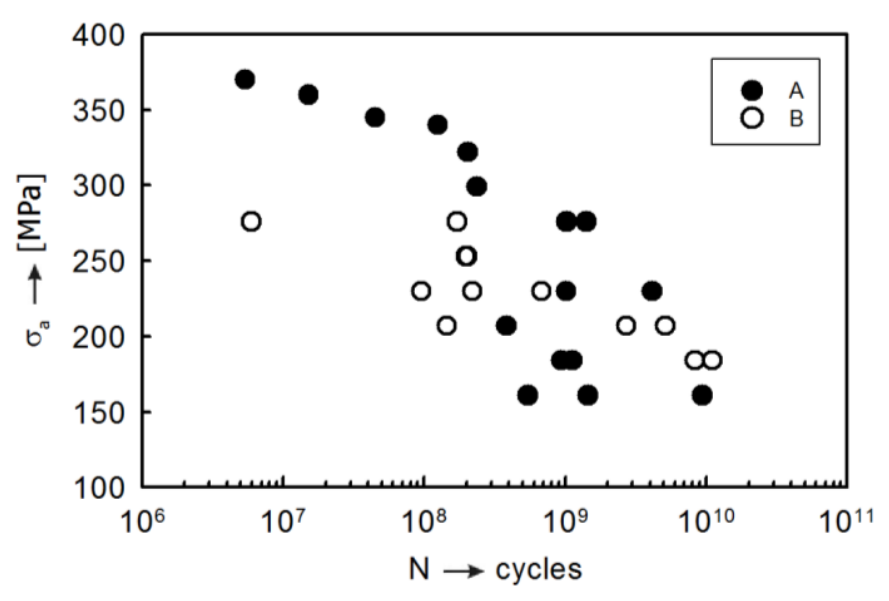

Fig. 9. Fatigue life curve, $\sigma_{\mathrm{a}}=\mathrm{f}(\mathrm{N})$

Above listed casting microdefects have a significant influence on the initiation stage of the fatigue process. The time after fatigue crack initiation required to the propagation of fatigue crack to such a degree that fracture occurs in the high cycle region is an only negligible fraction of the total fatigue life of the testing specimen.

Fractographic analysis of the LGG specimens broken during the fatigue tests reveals, that similarly, as in the low cycle fatigue, even in the fatigue tests in the very high cycle region there are two principal factor, affecting the fatigue life (in the material quality point of view) namely: location and size of casting microdefects. These effects were more obvious in fatigue tests in the very high cycle region, due to prolonged initiation stage, when compared with the low cycle fatigue testing. The micro defects connected with the surface of the testing specimens (Fig. 10) are from the initiation of fatigue crack point of view, the second most dangerous, immediately after the macroscopic defects, in which the initiation stage is shortened to almost zero. Microdefects in the near subsurface layers (Fig. 11) are also very detrimental, as they significantly accelerate the fatigue crack initiation process. Microscopic casting defects, which are dispersed in the volume of the testing specimens rarely serves as the fatigue crack initiators. In case of the fatigue crack initiation on the isolated microscopic defect in the bulk material, in the most cases, this initiation of the fatigue crack occurs on the larger cluster of defects, while very important role plays the notch effect and the stress fields surrounding the defect. The assessment of the notch effect of microscopic casting defects is generally very complex process and brings with it many dangers, on which the fatigue life estimations can easily fail. This is mainly related to the existence of very complex stress fields around the microscopic casting defects. 


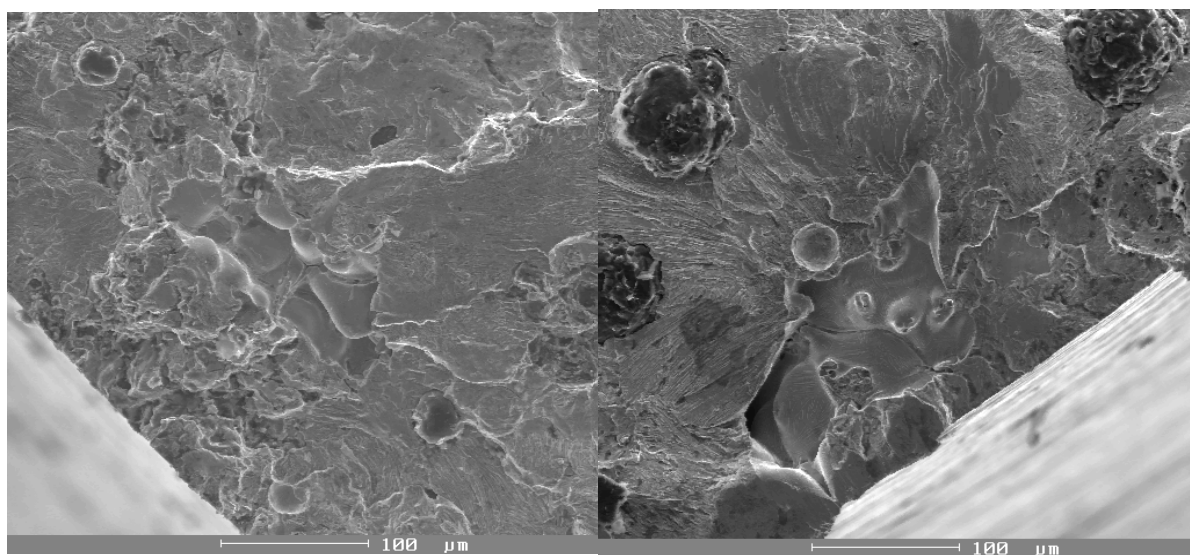

Fig. 10. Iniciation of the fatigue crack from the surface casting defect
Fig. 11. Initiation of the fatigue crack from the subsurface casting defect

In many cases can occurs that the part of the fracture surfaces with a local occurrence of a cluster of microscopic casting defects do not exhibit any signs of fatigue failure (Fig. 12). In these cases, is common that the crack tip missed the microscopic defects and the area containing microdefects broke suddenly due to local overloading. As the primary initiation sites for LGG without any macroscopic casting defects are considered microcavities and the agglomerates of graphite particles which come to the surface.

Interaction of propagating fatigue crack with the microscopic defect is much more complicated and usually requires an individual approach on the case-by-case basis. There is no way to automatically assume that if there is a casting microdefect near the tip of the fatigue crack, this crack will propagate towards it. In many cases could be observed, that propagating fatigue crack in the in close proximity miss the defect, or the crack pass just through its edge and continuous in the propagation perpendicular to the load direction without deviation or branching (Fig. 13), which would be often mistakenly expected from it. On the other hand, there are also opposite cases, when the crack is unexpectedly deflected from its original direction of propagation, due to at first sight, insignificant defect, which seems to be in the sufficient distance from the former direction of crack propagation.

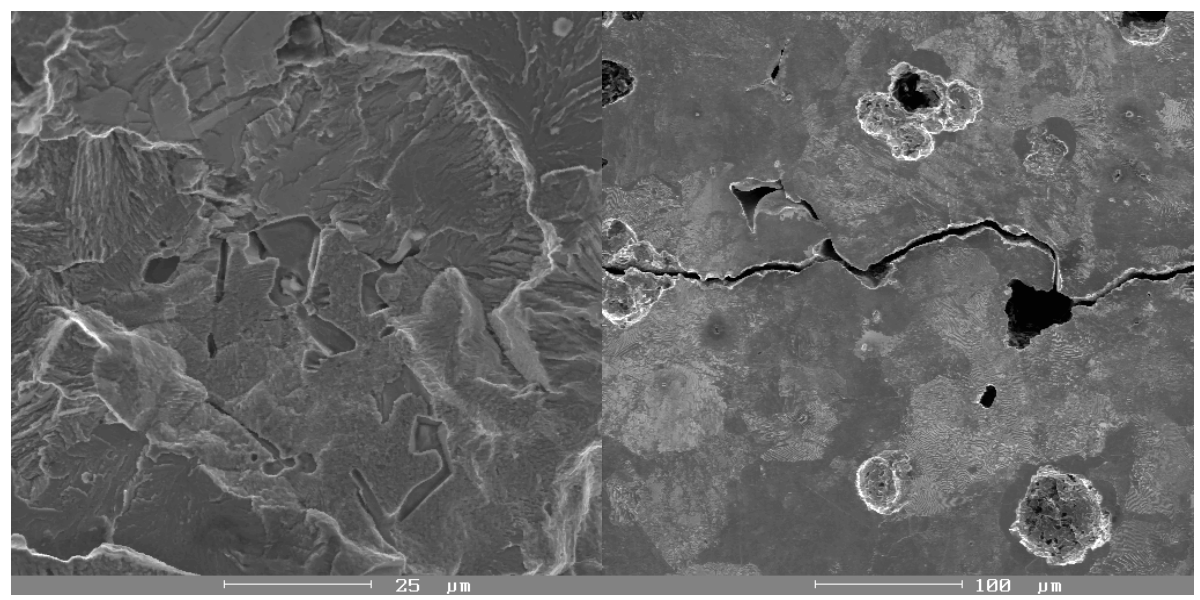

Fig. 12. Cluster of microcavities on the fracture surface
Fig. 13. Fatigue crack propagation (surface of the specimen for the fatigue crack propagation rate evaluation) 


\section{Conclusions}

In this paper, authors present fatigue tests results of the pearlitic-ferritic and ferritic-pearlitic LGG in the high cycle $\left(N \approx 10^{8}\right.$ cycles $)$ and the very high cycle region $\left(N \approx 10^{10}\right.$ cycles $)$ obtained by the high-frequency loading. For both examined LGGs, the dependence $\sigma_{a}=f$ $(N)$ has a decreasing tendency in the investigated interval. With the increasing number of loading cycles substantially increases the scattering of the fatigue life values, which is mainly caused by the extension of the initiation stage of the fatigue process. The length of the initiation stage depends on the presence of microscopic casting defects, with the most important factors were their position and size.

The increase of fatigue life of LGG casting can be successfully achieved mainly by improvements in the casting technology, which can prevent the formation of casting defect as cavities and microcavities. In particular, the following improvement should be taken into account:

- Provide a suitable composition of the molding mixture and its moisture.

- Provide sufficient permeability for molds and cores (reduce gasification level of the molten metal as are microbubbles).

- Ensure adequate collapsibility of the form.

- If it is feasible, do not make large differences in the thickness of the castings parts and the sharp transitions between them.

- Optimize the molten metal supply.

- Ensure a directed solidification of the casting by the use of suitable placed risers and chills.

- Choose an appropriate temperature of casting and ensure sufficient molten metal supply thought risers.

The research was supported by Scientific Grant Agency of Ministry of Education, Science and sport of Slovak Republic and Slovak Academy of Sciences, grants VEGA No. 1/0951/17 and No. 1/0123/15 and project "Research Centre of the University of Žilina, $2^{\text {nd }}$ phase", ITMS 26220220183.

\section{References}

1. R. Konečná, M. Kokavec, G. Nicoletto, Surface conditions and the fatigue behavior of nodular cast iron. Procedia Engineering 10, 2538-2543 (2011)

2. A. Vaško, L. Trško, R. Konečná, Fatigue behavior of synthetic nodular cast iron. Metalurgija 54 (1), 19-22 (2015)

3. A. Vaško, M. Vaško, J. Belan, E. Tillová, Comparison of fatigue properties of nodular cast iron at low and high frequency cyclic loading. Procedia Engineering 177, 576-581 (2017)

4. A. Vaško, J. Belan, L. Kucharíková, E. Tillová, Low and high frequency fatigue tests of nodular cast irons. Metalurgija 56, (1-2), 25-28 (2017)

5. R. Konečná, G. Nicoletto, L. Bubenko, S. Fintová, A comparative study of the behavior of two heat-treated nodular cast irons. Engineering Fracture Mechanics 108, 251-262 (2013)

6. Y. Nadot, J. Mendez, N. Ranganathan, Influence of casting defects on the fatigue limit of nodular cast iron. Internation Journal of Fatigue 26, (3), 311-319 (2004)

7. L. Collini, A. Pirondi, R. Bianchi, M. Cova, P. P. Milella, Influence of casting defects on fatigue crack initiation and fatigue limit of ductile cast iron. Procedia Engineering 10, 2898-2903 (2011) 
8. N. Shiraki, T. Watanabe, T. Kanno, Relationship between Fatigue Limit and Defect Size in Spheroidal Graphite Cast Iron with Different Graphite Spheroidization Ratios and Microstructures. Material Transactions 56, (12), 2010-2016 (2015)

9. T. Elbel, F. Havlíček, P. Jelínek, P. Levíček, J. Rous, K. Stránský. Defects of castings produced from iron alloys. (MATECS, Brno, 1992)

10. O. Bokůvka, G. Nicoletto, M. Guagliano, L. Kunz, P. Palček, F. Nový, M. Chalupová, Fatigue of materials at low and high frequency loading. (EDIS ŽU, Žilina, 2015)

11. F. Nový, M. Činčala, P. Kopas, O. Bokůvka, Mechanisms of high-strength structural materials fatigue failure in the ultra-wide life region. Materials Science and Engineering A 462, 189-192 (2007) 